\title{
Ambiguidades do momento corporativo: gênese e justificação dos direitos sociais no Brasil
}

Ambiguities in the corporate moment:

genesis and justification for social rights in Brazil

No início da década de 1930, a penetração do Estado no campo das políticas sociais sinalizava um forte deslocamento das convicções políticas e ideológicas que até então haviam organizado a cena pública nacional. As diversas instituições que iam surgindo acabavam por promover uma significativa incorporação de agendas sociais que até então estiveram submetidas à administração da esfera familiar, empresarial ou no socorro aleatório da caridade religiosa.

Como fruto dessa nova diretriz, que dizia assumir a segurança social como "problema fundamental do Estado", surgia o Ministério da Educação e Saúde Pública (Mesp) e o Ministério do Trabalho, Indústria e Comércio (MTIC). Para efeito de análise, esta formatação ministerial pode ser lida como o resultado de um diálogo descontínuo com algumas estruturas institucionais pregressas, o qual propiciou o reconhecimento e a inserção de novos atores no processo político. Como desdobramento desse diálogo, atacava-se, por um lado, o plano das desigualdades extremas que marcavam aquela ordem social, e, por outro, consolidava-se a prestação estratificada de um vasto campo de serviços sociais. No caso da atenção à saúde, a oferta diferenciada passava a consagrar uma cisão estrutural entre a saúde do trabalhador e os termos pelos quais se organizaria a saúde pública. A rigor, enquanto o MTIC assumia a prerrogativa de dinamizar os serviços

É doutor em ciência política pela Universidade Federal de Minas Gerais (Belo Horizonte, MG). E-mail: ronaldosann@gmail.com. 
de saúde ao contingente vinculado ao mercado formal de trabalho, o Mesp caracterizar-se-ia por um formato mais próximo de parâmetros universais de atenção e acesso (Fonseca, 2007).

Essa matriz de enfrentamento da questão social no Brasil tornou-se um dos temas mais controvertidos das ciências sociais brasileiras. Sobre esse assunto, a "cidadania regulada" de Wanderley Guilherme dos Santos (1994) tornou-se, sem dúvida, uma das interpretações de maior difusão. Além dela, a clássica interpretação de Malloy (1976) nos informa o alcance histórico desse diapasão analítico forjado no trauma do pós-1964. Por sua vez, o formato em questão pode ser considerado, como sugere Reis (1989), uma saída virtuosa à institucionalização precária que marcara a "questão social" nas décadas anteriores Em sua análise, essa estrutura seria parte de um desenvolvimento político que operava em termos de "distribuição" e "reprodução" do poder societário. Seguindo essa perspectiva teórica, o reconhecimento diferenciado de recursos de poder e mobilização política torna-se um parâmetro decisivo para se compreender não apenas a formação do novo modelo, como também o seu posterior processo de desenvolvimento institucional (Reis, 1989; 2000).

Considerando que esse sistema diferenciado de inclusão social por fim alcançou um significativo enraizamento histórico, assumimos como centro de nossa problematização que a "solução corporativa" não era, entretanto, um fato óbvio ou historicamente inevitável. Dito de outro modo, entendemos que a reprodução estratificada do acesso a serviços sociais percorreu um conturbado processo de maturação antes de encontrar certa estabilidade institucional e pragmática. Nesse sentido, se é possível falar que a referida cisão ministerial acomodou e agregou interesses diversos, mostrando-se "progressista" e "restritiva" a um só tempo, procuramos aqui evidenciar o seu controvertido e contingente processo de justificação.

Colocado dessa forma, o problema de pesquisa que nos orienta conserva em si um inegável esforço de historicização da experiência corporativa no Brasil. É a partir desse enquadramento que a "questão social", e particularmente a organização dos "serviços de saúde", nos interessa.

Perseguindo esse propósito, localizamos em um primeiro momento o ambiente político em que a razão corporativa veio a ser recepcionada. Ao problematizar o controvertido caldo de resistências em que esteve exposto, procuramos apontar a polissemia interpretativa na qual a "questão social" 
e o "mundo do trabalho" eram apreciados. Desse modo, na primeira seção, procuramos abrir portas à percepção de que a "solução corporativa" estava longe de alcançar um apoio coeso das classes patronal e trabalhista, apresentando-se, antes, como um grande contrassenso.

Após identificar esse cenário de disputa de narrativas, investigamos os mecanismos que conferiram legitimação à resolução corporativa das crescentes demandas por serviços sociais. Em torno desse ponto se organiza o tema central das últimas seções deste artigo, concentrado na formação intelectual e política de Oliveira Vianna. Reconhecendo-o com um homem do seu tempo, e sua obra como o "sujeito coletivo" de uma época, destacamos Vianna pela expressividade que foi capaz de conferir à emergência da tradição corporativa no Brasil. Em diálogo com as proposições de Ângela Gomes, o autor é aqui identificado como um statemaker, um "intelectual/ político". Isto se deve ao fato de que além de atuar em um contexto de intensa redefinição interpretativa da vida política brasileira, tornou-se também um "poderoso homem da burocracia do Estado" (Gomes, 2010, p. 210)1.

A título de conclusão, compreendemos que ao promover esse recuo temporal conferimos plausibilidade ao argumento de que o processo de politização da "questão trabalhista" e os vínculos que o tema estabeleceu com a "questão social" não se orientavam por uma semântica que tomasse os parâmetros universais de cidadania como uma dimensão robusta da arena política. Entendendo o corporativismo como um fenômeno político que transcende o plano institucional, por pretender orientar a "base social" na qual se davam os conflitos e as relações estratégicas de poder, apontamos que as narrativas concorrentes se viram parcialmente interditadas àquele contexto histórico.

\section{Um trabalhismo corporativo, pelo "bem da nação"}

A orientação corporativa que recepcionou a institucionalização dos direitos trabalhistas no Brasil tornou-se um tema controvertido desde

Inserindo-se na vida intelectual brasileira no início dos anos 1920, em pouco tempo Vianna se viu envolvido no centro dos debates mais polêmicos do seu tempo. Nos anos 1930, sua intensa atividade editorial estaria conciliada à condição de policy maker. Assim, como membro da comissão que elaborou o anteprojeto de Constituição encaminhado à Assembleia Nacional Constituinte de 1933-1934, chegaria à posição de consultor jurídico do recém-criado MTIC. Essa visão também é reforçada por Oliveira (1993), que chama a atenção para outros intelectuais que, àquele contexto, tiveram comportamento parecido. 
a sua criação. À época, as principais clivagens políticas podiam ser identificadas entre o setor urbano-industrial paulista e os sindicatos que haviam se formado nos anos 1910 e 1920 . Opositores e apoiadores podiam ser localizados tanto nas casas congressuais quanto nas organizações de classe. De um modo geral, o espectro das posições variava entre premissas liberal-conservadoras e orientações francamente socialistas (Gomes, 1979; Lowy, 1980; Vianna, 1999). Todavia, atendendo a motivações que se explicam pelas especificidades do contexto, é possível identificar uma pletora de interpretações e comportamentos cambiantes no interior desses dois espectros. Não raro, as convicções políticas e ideológicas deixavam de assumir lugares fixos, e mudavam suas posições e preferências iniciais.

Descendo às formas institucionais que conferiam realidade corporativa ao mundo do trabalho no imediato pós-1930, destaca-se o Decreto n. 19.770 promulgado em julho de 1931, também conhecido como Lei de Sindicalização. A imediata rejeição do trabalhismo organizado sob esse enquadramento legiferante deveu-se ao entendimento de que sua formalização traduzia o mais puro esforço de submeter e neutralizar os sindicatos mais combativos que haviam se formado nas décadas anteriores. Entre outras coisas, a nova legislação exigia dos "novos sindicatos legais" a "entrega ao Ministério do Trabalho de uma lista de seus integrantes", garantindo a esse órgão uma vigilância sem precedentes. De acordo com essa leitura de Lowy (1980), desde a promulgação desse decreto até a Constituição de 1934, a resistência generalizada aproximaria sindicatos anarquistas, comunistas e trotskistas, organizados em torno da Federação Operária de São Paulo (Fosp) e da Confederação Geral de Trabalhadores (CGT), respectivamente.

Não obstante o desagravo dos sindicatos mais combativos, que em um primeiro momento esforçaram-se para se manterem "independentes", o que se pode observar nos anos que se seguiram foi a constante ampliação dos ditos "sindicatos legais" (Gomes, 1988; Lowy, 1980; Segatto, 1989; Vianna, 1999). Como parte das idiossincrasias políticas que acompanham o tema em questão, diversos estudiosos identificam que essa ampliação contou com forte atuação do Partido Comunista Brasileiro (PCB), que, no pós-1934, obedecendo ao Manifesto-programa nacional libertador, passara a privilegiar a luta institucional por "assistência ao trabalhador" (Carone, 
1973; Segatto, 1989)². Essa orientação se consolidou nas décadas seguintes, como deixam evidentes a Resolução Sindical de 1952 e a Declaração de Março de 1958 (Segatto, 1989).

Entre 1930 e 1937, a posição patronal em relação à orientação política que dava forma ao novo bloco governista dividiu-se entre a resistência constante e o apoio pontual (Gomes, 1988). A primeira posição devia-se ao crescente controle político e econômico que o novo padrão institucional representava sobre suas organizações. Todavia, ao vociferar contra o novo código de leis de proteção ao trabalho e contra a nova política de segurança social, alimentavam, também, uma crescente simpatia pelo viés autoritário a que eram submetidas as organizações de classe do trabalhador urbano (Gomes, 1979; 1988) ${ }^{3}$.

Transbordando o acalorado debate verificado na imprensa operária e nos veículos de grande circulação, as pesquisas de Werneck Vianna (1999) e Ângela Gomes (1979) nos permitem afirmar que o tema não era menos controvertido nas arenas congressuais. O contraponto empresarial à Lei de Férias, ao Código do Menor e à Lei das Caixas de Seguros Contra Doenças, debatido na Câmara e no Senado entre 1933 e 1934, herdava, em larga medida, o núcleo da lógica argumentativa forjada nas décadas anteriores (Gomes, 1979) ${ }^{4}$.

Compreende-se que a construção autoritária do acesso corporativo aos direitos sociais, ao impor limites ao ânimo irrefreado de lucro e ao interditar a mercantilizacão sem peias dos valores e dos bens sociais, instalava-se fora dos postulados políticos liberais e comunistas clássicos ${ }^{5}$. Nessa toada, incorporava parte das bandeiras trabalhistas ao avançar na redução de

2 De acordo com a análise de Carone (1974), a entrada de "tenentes de esquerda" no PCB, egressos da Coluna Prestes, teve fortes consequências no realinhamento político ideológico do partido, que passava a assumir uma tendência social menos isolacionista. Essa leitura é endossada por Segatto (1989).

Como conclui Gomes (1979, p. 214), a "atuação da burguesia urbana" se limitava a concentrar esforços na alteração da dinâmica de regulação do mercado de trabalho. Conforme avançava a referida década, "sua maior vitória" se situava no "retardamento do ritmo do processo".

4 A posição do patronato urbano em relação à nascente regulação corporativa da questão social e trabalhista é objeto de divergência entre Werneck Vianna e Ângela Gomes. Para Vianna (1999, p. 159), depois de 1932 a burguesia industrial "assume-a cada vez mais francamente", ao passo que, para Gomes (1979, p. 219), desde o pós-1930 a rejeição do empresariado ao registro legal corporativo seria um fato explícito.

Como se discute adiante, parte das tensões políticas que esse corporativismo representava diante de outras tradições que se encontravam disseminadas no mundo do capital e do trabalho funda-se no seu ideal comunitário cristão. Assim, ao dialogar com os princípios de harmonia e cooperação, submetia o conflito social a certa moralidade coletiva (Riquelme, 2009). 
graves assimetrias sociais. Paralelamente, se esforçava para limitar a ação política da classe operária, conquistando, assim, uma simpatia precária do setor patronal.

Até aqui, importa-nos destacar que o meio-termo entre a forte resistência e o apoio circunstancial à "nova política social" operou de forma seletiva na posição política que assumiam patrões e empregados. Em que pese essa transitividade de posições, que ocasionalmente servia à revisão das posições mais ortodoxas dessas classes, seria possível identificar o ponto comum de unidade nessa resistência: a natureza marcadamente corporativa do projeto social que estava em curso.

Aqui, o "contexto das ideias" nos coloca em diálogo com certas proposições analíticas que estruturam o institucionalismo de Margareth Weir (1992). Recorrendo à autora, entende-se que o corporativismo assume a dimensão de uma "filosofia pública" e de "ideia programática". Ao condicionar os termos do debate público a partir de suas categorias e princípios, ele matizaria a organização de importantes políticas sociais, caracterizando um novo processo de State building. A rigor, o que se quer apontar são os contornos estreitos entre o plano institucional que se formava e o caráter inconcluso das disputas políticas que estavam em curso no plano social ${ }^{6}$. Dito de outro modo, até se consolidar como lógica da administração pública, a linguagem corporativa teria um tortuoso caminho a percorrer.

Não por acaso, imersos no calor dessas intensas disputas, muitos dos livros de Oliveira Vianna assumiriam uma face abertamente polemista. Essa característica ajuda a delinear não apenas o cenário no qual se encaixa sua obra e atividades programáticas, mas também a sua relevância teórica e política para o contexto.

\section{Oliveira Vianna e a justificação pública do acesso corporativo aos direitos sociais}

Encontrando Oliveira Vianna nesse controvertido percurso de legitimação, a reafirmação da "questão social" no país e os seus vínculos com a incorporação institucional do trabalho compunham um debate que

O diálogo com as preocupações teórico-metodológicas de Weir (1992) busca enfatizar o repertório das linguagens políticas que à época repunham o corporativismo à condição de "filosofia pública". Desse modo, ao historicizar a gênese do corporativismo no plano nacional, procura-se aqui observar narrativas interpretativas dissonantes, que, mesmo configurando o debate público, foram porventura suprimidas ou incorporadas lateralmente ao novo plano institucional que se idealizava. 
já possuía certa inscrição histórica. Como apontou Bosi (1995), a busca do equilíbrio e da harmonia entre o capital e o trabalho já se fazia presente no Brasil na virada do século XIX ao XX. Para além de Oliveira Vianna, a valorização de um Estado autoritário e corporativo também pode ser localizada em outros destacados pensadores da época, como Alberto Torres (cf. Souza, 2005), Francisco Campos (1940) e Azevedo Amaral (1941). Nesse sentido, o pensamento de Vianna é uma unidade que se articula com um campo intelectual mais amplo.

Todavia, ao configurar amplitude aos anunciados de sua época, é possível argumentar que o amadurecimento teórico e a expressividade empírica do corporativismo ganharia consistência com a imersão de Vianna no MTIC, a partir de 1932. Em outras palavras, seria com Oliveira Vianna que o debate passaria a ser informado por categorias conceituais sistematizadas, assumindo o estatuto de "filosofia publica" e de "ideia programática"7.

De acordo com Botelho (2010), desde o século XIX era comum a muitos intelectuais a tese de que a coordenação de interesses privados no Brasil corrompia a construção de uma ordem social efetivamente pública. No caso de Vianna, pesava sobre esse diagnóstico a compreensão de que o "complexo cultural insolidário" do brasileiro definiria o fracasso operacional das instituições que até então haviam sido idealizadas no país ${ }^{8}$.

Em Oliveira Vianna, o “insolidarismo” é condição decisiva para a improcedência do léxico liberal que havia condicionado o desenho institucional brasileiro desde a Constituição de 1891. Seu entendimento era de que a rarefação desse espírito gregário interditava completamente a realização de uma cidadania política, conforme apontava a experiência anglo-saxônica. Assim, mesmo declarando admirar o "igualitarismo da França de Rousseau", compreendia, entretanto, que o nosso "caldo

\footnotetext{
Ao contrário do que aponta Vieira (1976), que entende que a"questão social"só se torna "conhecimento vivo" no Brasil com o advento da "questão corporativa", para Alfredo Bosi (1995), a invenção social do trabalho já se expressava nos primeiros anos do século XX. Aproximando a fundação das questões sociais ao argumento positivista autóctone, Bosi proporciona elementos que elucidam as raízes do diapasão doutrinário ao qual se afinaria a organização social e trabalhista da futura nação brasileira no pós-1930.

8 O próprio autor menciona reiteradamente essa análise em várias de suas obras. Procurando enfatizá-la, registra sua passagem nos livros Problemas de política objetiva (1930), Instituições políticas brasileiras (1949a), Problemas de direito corporativo (1938) e Problemas de direito sindical (1943).
} 
cultural" inviabilizava a realização da justiça social por esse caminho (Vianna, 1949b, p. 216) ${ }^{9}$.

Tendo em vista essa condição, Oliveira Vianna chegaria a outra "ideiaforça" que caracteriza seu pensamento: o corporativismo. Esse apontamento assume seus primeiros contornos em Problemas de política objetiva (1930); outra apreciação sistemática do tema seria apresentada apenas oito anos depois, em Problemas de direito corporativo (1938), e ainda em Problemas de direito sindical (1943). Nesse contexto, assumindo a condição de pedra angular da "nova política social", como definida na Constituição de 1937, o corporativismo passaria a organizar as bases do novo Estado e da nova nação pretendida. Em Direito do trabalho e democracia social (Vianna, 1951), a crescente relevância política do argumento corporativo passaria a ser claramente justificado no interior da Doutrina Social da Igreja (DSI), a qual se estabilizaria como a melhor tradução do espírito político e social do brasileiro.

Em linhas gerais, o corporativismo seria entendido como chave única para a superação das desigualdades extremas que então se verificava na sociedade brasileira. Ao funcionar como mecanismo propulsor de solidariedades mais amplas, a distribuição corporativa de diversos benefícios sociais, como saúde e previdência, serviria à superação do "insolidarismo", "maior patologia da política nacional". Por esse percurso, as organizações sindicais passariam a assumir decisivo relevo em seu pensamento, e a regulação do mundo trabalho se tornaria condição incontornável à solução das carências políticas e sociais diagnosticadas. Resumidamente, a institucionalização corporativa dos direitos sociais consistiria em proteger o elemento brasileiro contra o arbítrio ilimitado que até então caracterizava sua relação assimétrica com a classe patronal (Vianna, 1951).

As reflexões de Vianna em relação ao desenvolvimento institucional corporativo repõem claras implicações sobre o plano da cultura política. Por esse aspecto, suas considerações acerca do corporativismo não se reduziriam a uma dimensão exclusivamente institucional. Conforme o autor, se "nenhum homem nesta terra é republico", o fomento do espírito

É interessante documentar que a leitura de Oliveira Vianna sobre os fundamentos políticos da cidadania em Rousseau aparece vinculada à tradição liberal. Apesar de crítico ao individualismo moderno, o autor lê o primado da cidadania ativa e da soberania popular como atributo da democracia liberal. Uma agenda interessante seria investigar como esse olhar sobre a filosofia política interfere no horizonte normativo de Vianna. 
coletivo se processaria com a entrada dos indivíduos no universo do trabalho formal (Vianna, 1951). Ao que parece, seria na busca de realização do autointeresse econômico que a coesão social se processaria, iluminando a formação de algum "espírito cívico".

Essa proposição analítica suscitou leituras que passaram a situá-lo como um dos grandes representantes da teoria do Estado autoritário no Brasil (Rodriguez, 1997; Vieira, 1976) ${ }^{10}$. No interior dessa crítica, a condição demiúrgica e pedagógica do Estado compareceria a partir de uma autonomização das instituições frente aos valores e práticas sociais, tornando-se uma realidade per se.

Atestamos que essa condição está realmente presente em Vianna, mas não resume a totalidade da sua "teoria do Estado". Isso se deve, precisamente, ao virtuosismo das leis e ao fato de que sua capacidade de redesenhar os vícios costumeiros do "povo-massa" não pode ser descolada da história social que informa sua análise. Para o autor, "A sociedade existe, encerra forças incoercitíveis e incompreensíveis, com que o Estado, apesar da sua onipotência atual, tem que contar se não quiser fracassar nas suas tentativas de reforma ou de transformação da sociedade" (Vianna, 1943, p. 243-4, grifos nossos).

Nas formulações de Vianna existe, sim, uma "elite técnica e iluminada", capaz de se colocar acima da política e das classes sociais. Todavia, esta não apenas coage, como também dialoga e resgata a cultura popular. Ao reafirmar que o "Estado diretor" firma sua autoridade reconhecendo o povo, compreende-se que o autor voltava sua atenção aos limites de se impor uma institucionalidade "de cima para baixo" ou "independentemente da sociedade". Por tais motivos, é preciso não confundir a condição apolítica das elites com a dimensão pedagógica do Estado, e reconhecer que o segundo aspecto não se funda em um arbítrio unilateral. Assim sendo, o "Legislador" de Oliveira Vianna não gozaria do virtuosismo institucional que muitos analistas lhe imputam, uma vez que seus pressupostos teóricometodológicos tencionam o entendimento que toma o tecido societário como um resultado exclusivo da ação estatal.

10 Nos anos 1970, uma variante dessa proposição crítica se formaria denunciando a mistificação a que eram repostas as categorias de povo e de nação. Discutindo a experiência política brasileira a partir do conceito de Estado burocrático-autoritário, diversos intelectuais perceberam o corporativismo como uma ideologia que se esforçava em suprimir os interesses classistas, resultando no bloqueio das forças democráticas no Brasil (Schwartzman, 1977; Lamounier 1985; Cardoso, 1979). 
Botelho (2010) entende que o institucionalismo de Vianna é incompreensível se não se coloca a sociedade em primeiro plano. Seria muito forte no autor fluminense a crítica aos "bacharéis brasileiros" que, "distantes do direito criado pelas massas", teriam forjado nas instituições um código de regras alheio às normas espontâneas da sociedade. Pode-se dizer que Vianna (1938; 1949a), avesso ao formalismo jurídico, procurou estruturar seu campo analítico denunciando o descolamento do "direito lei" do "direito costumeiro". Sob essa perspectiva, ao tomar os condicionantes da política como elemento de análise, o autor não se fecharia nos legados institucionais, e a validação de tais heranças só seria sensível quando fossem capazes de se reproduzir no terreno da práxis - ou seja, na condição de comportamento legitimado no plano das ideias políticas. Daí que a semântica institucional seria apenas um momento entre outros em que se legitimariam as práticas sociais. De acordo com Botelho (2010, p. 14), a dimensão demiúrgica do Estado, se pensada do ponto de vista do puro "voluntarismo" institucional, deveria ser considerada apenas como um "princípio contingente e descontinuo ao longo de sua obra”.

É interessante ressaltar, no entanto, que a clara importância que os fundamentos sociais tinham para a formação do Estado em Oliveira Vianna foi insistentemente associada a uma suposta "passividade política" secular do "elemento brasileiro". Como efeito, o "complexo cultural" desse "povomassa”, identificado na formação, na evolução e no funcionamento do Estado, foi tomado como expressão de sua incapacidade de autoformação política. De nossa parte, entendemos que essa condição de subalteridade não se apresenta consistentemente no autor como uma fatalidade histórica insuperável ${ }^{11}$.

Sabe-se que a proposição de impulsionar a construção nacional comparece no autor como parte de uma transformação processada também no plano moral e cívico. Nesse sentido, ao tomar a "cultura popular" como premissa, o desenho institucional que dela resulta passa a ser justificado

1 Uma leitura da relação entre cultura e política em Oliveira Vianna pode ser localizada em Sérgio Buarque de Holanda (1979). Segundo ele, os estudos da cultura em Vianna cederiam espaço a uma apreciação "imanente"e"proto-histórica" das ideias políticas, de forma que estas seriam percebidas como parte da "própria fisiologia dos indivíduos" (Holanda, 1979, p. 49). Por essa abordagem, nos parece que Holanda se ocupa de fundamentar uma crítica antes à forma como Oliveira Vianna percebe a formação da cultura do que às implicações desse método para o desenvolvimento institucional, como proposto pelo pensador fluminense. 
como parte de um diálogo orgânico com essa realidade sociocultural. Por tais vias, o corporativismo não seria pura exterioridade epistemológica, por resultar de uma situação objetiva, assim como a democracia estava colocada para os povos europeus.

Assim compreendido, é possível identificar, senão uma ambiguidade, pelo menos uma forte tensão analítica em suas reflexões: se, por um lado, a construção corporativa do acesso a políticas sociais traduzia, em parte, o que já existia como "direito costumeiro" no Brasil, por outro, ela deveria corrigir os vícios da cultura política nacional. Em outras palavras, a estrutura corporativa, discutida como profilaxia mais contundente do "insolidarismo" crônico que fundamentava a arena política nacional, também encontrava aderência nas práticas políticas virtuosas desse "povomassa". Cabe interrogar em que momento se daria esse ajuste.

A menção ao caráter genuinamente autóctone da "nova legislação social" transparece em muitas passagens de Problemas de direito sindical. Procurando se proteger dos críticos que reiteradamente lhe imputavam o estigma do estrangeirismo fascista, advogava que a nova legislação sindical obedecia a uma "metodologia objetiva e investigadora" (Vianna, 1943). Assim, apesar do seu "impulso vir de fora”, seria em diálogo com a tradição que a nova legislação social corporativa se explicava, uma vez que se ancorava no que havia de mais genuíno na "índole [...] e na alma da nossa gente" (Vianna, 1951, p. 115).

Reforçando essa tese, afirmava: "O mérito dos técnicos do Ministério, que presidiram as comissões elaboradoras dos ante-projetos, foi antes de sistematização de um direito já existente do que propriamente da criação de um direito novo" (Vianna, 1949, p. 32). Por tais vias: "O nosso direito do trabalho [...], ficou sendo assim, o nosso direito costumeiro, elaborado pela atividade espontaneamente normativa das nossas próprias massas trabalhadoras" (Vianna, 1949, p. 33, grifos meus). Nisso residira a força institucional da Consolidação das Leis do Trabalho (CLT), de 1943, servindo à superação da dicotomia entre o "Brasil real" e o "Brasil legal"12.

2 Em Direito do trabalho e democracia social (1951), Vianna é ainda mais enfático. Ao reconhecer as influências teóricas exógenas, enfatiza, como um "ato de justiça", que em "nossa legislação social [...] há um sainete brasileiro inegável, uma viva impregnação de brasilidade, forjadas como foram elas [...], sob a pressão dos fatos, à luz da experiência cotidiana" (Vianna, 1951, p. 76-7). 
Seguindo essa orientação analítica, os institutos profissionais e as associações sindicais representariam, no pós-1937, a "reorganização" do que já existia, mas sob condições completamente novas. Assim, apostando no enraizamento social dessas instituições, Vianna atestaria que "não nos foi preciso atacar ou destruir coisa alguma da nossa velha ordem tradicional e das nossas tradições cristãs", uma vez que: "Nada do que foi realizado no domínio da proteção e do amparo ao trabalhador viola ou fere o nosso patrimônio moral e o nosso tradicional senso de justiça e moderação" (Vianna, 1951, p. 143, grifos do autor).

O tom laudatório dessas afirmações sobre o "caráter brasileiro" chama atenção. Como se sabe, não é esse recorte que predomina na extensa obra do autor, nem é o que recorrentemente se encontra registrado pelos seus principais interpretes. Assim, em que pese a afirmação desse espírito gregário como "estado rudimentar e descontinuo", vale documentar o deslocamento promovido por tais passagens, reiteradamente repetidas nos seus escritos de 1951.

O ponto é que o traço insolidário encontraria registro nas "populações rurais", ao passo que a "nova legislação social" tinha suas raízes costumeiras nas "populações urbanas e marítimas”. Os vínculos sociais da legislação corporativa se reduziriam ao "perímetro das cidades" e a elas se aplicariam, uma vez que "o mundo rural brasileiro continua intacto, fora da ação tutelar e renovadora desta nova política social” (Vianna, 1951, p. 16). Ao reconhecer essa cisão, o autor promoveria certo descolamento do produtor e do trabalhador urbano, em relação ao "povo-massa", do meio rural. Com esse procedimento, Vianna continuaria coerente com a sua teoria social das instituições, conforme salientou André Botelho ${ }^{13}$.

Vale registrar que se, com a Lei Eloy Chavez, de 1923, esse desenho já se anunciava, nada permite afirmar que houvesse um reconhecimento generalizado de que o acesso a direitos deveria se dar via corporações. Recorrendo ao estudo da imprensa operária dos anos 1920, Edgard Carone (1979) oferece elementos que não vinculam a demanda do "movimento

\footnotetext{
${ }^{3}$ Em Problemas de direito corporativo, Vianna (1938) também procura identificar evidências empíricas que demarcariam a passagem do espírito clãnico e individualista às experiências do "meio contratual coletivo". Nessa obra, dedicando-se à defesa da Justiça do Trabalho, investiga evidências empíricas que legitimavam a nova legislação social corporativa. Por tais vias, o autor procurava registrar que ao se valer amplamente das experiências em curso no plano internacional, nada mais fazia do que delinear as especificidades de práticas observadas entre os marítimos e os ferroviários.
} 
trabalhista" ao léxico pragmático corporativo. Como esse autor deixa claro, a luta operária por dignidade envolvia "o trabalho na fábrica", a "elevação cultural", a "vida na casa e no sindicato" e a "participação política". Reiteradamente, os panfletos trabalhistas demandavam uma "dignidade humana" que inseria o debate sobre "legislação trabalhista" para além das categorias laborais. A literatura sobre o movimento operário no Brasil aponta regularmente para essa direção (Basbaum, 1976; Carone, 1979; Dias, 1977; Fausto, 1983; Rodrigues, 1969) ${ }^{14}$.

Cotejar tais distâncias interpretativas não impede o reconhecimento de que a institucionalização da agenda social nos anos 1930 manteve diálogo significativo com as bandeiras trabalhistas das décadas anteriores. Esse argumento, presente na reconhecida tese de Gomes (1988), não ignora a tensão política e ideológica que perpassava esse “diálogo". É um argumento comum entre historiadores que, desde o fim do século XIX, para além da intensa presença católica, a polissemia interpretativa da causa trabalhista era disputada também por leituras comunistas e pela tradição anarcossindicalista (Basbaum, 1976; Carone, 1979; Dias, 1977; Fausto, 1983). Como se sabe, em tais campos, a compreensão de Estado, de práxis política e, por conseguinte, da oferta de direitos, guiava-se por outra plausibilidade lógico-argumentativa.

Como já destacado, a maior parte da legislação trabalhista encarregada de traduzir o acesso estratificado aos direitos sociais é anterior à presença de Oliveira Vianna no MTIC (Gomes, 1979) ${ }^{15}$. Todavia, como se está procurando registrar, a justificação corporativa e o sentido público mais amplo que o "programa de 1930" assume não tinha o corporativismo como orientação sistematizada, previamente constituída.

Aqui não se pressupõe uma transposição mimética das "ideias políticas" de Oliveira Vianna ao desenho institucional que se formava. Situá-lo no vértice de debates políticos e intelectuais que marcaram a construção e o

14 De acordo com Ferreira e Gomes (2001), uma retomada desse "passado glorioso" esteve na base da literatura que se encarregou de analisar o "novo sindicalismo" que surgiu no fim de 1970. Superando o largo intervalo "populista" e "pelego" que sequestrou o sindicalismo a partir de 1930, o "novo sindicalismo" guardaria aproximações com a suposta autenticidade política e ideológica verificada no trabalhismo das décadas de 1910 e de 1920.

15 Os decretos que iriam compor a obra social no pós-1930 atestam uma intensidade legiferante já no início de sua formação. Entre 1931 e 1933 foram promulgados nada menos que nove decretos-lei na área social. Para informações mais detalhadas, ver Vianna (1999, capítulo 3). 
esforço de legitimação da legislação trabalhista, sindical e previdenciária não significa suprimir as particularidades que demarcam essas categorias de análise. Também não significa desconhecer que o autor se inseria em uma "comunidade de sentidos". O registro que se pretende consiste em matizar o repertório dos vínculos teórico-normativo e político-ideológico entre o conjunto de suas ideias e o plano institucional legal que assumia validade histórica. Sendo possível verificar uma proximidade léxica entre seus argumentos e a norma jurídica em questão, é plausível defini-lo como ponto forte de uma narrativa que insistia em assumir a direção política de um novo projeto de Estado, de nação e de cidadania que estavam em curso.

Nesse controvertido processo de legitimação da razão corporativa, a "nova política social" insistia em introduzir a cidadania no país pelo mundo do trabalho. Para tanto, o pragmatismo corporativo não apenas deveria estar submetido ao "interesse público", como seria também sua melhor tradução. Buscando subsídios para reafirmar que o conflito distributivo trabalhista era uma questão afeta ao direito público, submetido, portanto, ao escrutínio do Estado, o autor dizia-se em sintonia com o que havia de mais avançado no direito moderno (Vieira, 1976). A rigor, a "solução sindical" consistia em retirar o "problema social" do "direito privado da produção", submetendo-o aos parâmetros públicos de regulação e controle ${ }^{16}$. Com esse movimento, a reprodução dos direitos sociais, dentre eles os serviços de saúde e previdência, encontrariam desenvolvimento dinâmico via contrato coletivo e negociação coletiva do trabalho. Como parte dessa composição, as organizações de classe funcionariam como canais de participação e de representação dos "verdadeiros interesses do povo brasileiro" (Vianna, 1938, p. 61). Decorre daí o seu esforço em formalizar o poder normativo da justiça do trabalho, da unicidade sindical e do imposto sindical compulsório. Nesse mesmo sentido, devem ser compreendidas as discussões em torno do Decreto n. 1402 de 1939, cujo artigo 4ํㅡㄹ declarava ser responsabilidade das organizações trabalhistas e patronais "fundar e manter escolas, especialmente, hospitais e outras instituições de assistência social" (Vianna, 1951, p. 55).

A estreita relação que se quer evidenciar entre as proposições intelectuais e o projeto político-ideológico que balizava a institucionalização do acesso

${ }^{16}$ Para mais detalhes, ver Gomes (1993, p. 317-52). 
corporativo aos direitos conduziu Oliveira Vianna à condição de policy making. Interferindo no debate público e procurando dar sentido concreto às suas proposições teóricas, entende-se que o edifício jurídico perseguido por Oliveira Vianna mostrava grande coerência em sua orientação teórica e política. Era a força dessas proposições que aos poucos ia conferindo legitimidade à reprodução do acesso estratificado aos serviços de saúde via MTIC, por exemplo. Isso revela que o acesso às questões que envolviam a saúde do trabalhador e seus dependentes, via pragmatismo sindical, foi vivamente perseguido por Oliveira Vianna.

É preciso compreender que o "trabalhismo" e a "questão social" abrigavam também uma dimensão moral, que se endereçava à formação cívica do trabalhador brasileiro. Como estamos discutindo, o novo código de direitos trabalhistas, sindical e previdenciário configurava um projeto de formação nacional, para a qual era preciso haver uma "nova mentalidade", um outro "espírito público". Resolvendo institucionalmente o problema da "presença do povo junto ao Estado", se objetivava a "elevação e a dignificação progressiva das classes trabalhadoras dentro do regime capitalista", ainda que não se rompesse com as hierarquias sociais e o regime de propriedade (Vianna, 1951). Atuando, assim, sobre a vida do trabalhador na empresa, no Estado e na sociedade, desmercantilizava-se o trabalhador e conferialhe "elevação moral". Com esse movimento, Oliveira Vianna se distanciava das gramáticas liberal e comunista que até então predominavam como horizonte explicativo dos conflitos modernos.

\section{A cidadania corporativa e a social democracia cristã}

A afinidade eletiva entre a vida intelectual e burocrática de Oliveira Vianna e os fundamentos da DSI comparece de forma mais explicita e consistente em Problemas de direito sindical (1943), e Direito do trabalho $e$ democracia social (1951). Conforme Vieira (1976) identificou, o pensamento corporativo em Oliveira Vianna orientou-se por fontes diversas. Afinado com a produção intelectual de seu tempo, sua inspiração percorreu destacados autores da doutrina corporativa seja no plano nacional ou internacional. Em meio a essa gama de influências, compreende-se que é possível e frutífero situar em duas dimensões o seu campo de reflexões sobre o corporativismo: a primeira, voltada para uma ciência do Estado corporativo, ocupada, entre outros pontos, com as questões afetas a 
uma representação político-institucional alternativa ao modelo liberal; a segunda, na qual o autor cultivava os vínculos do corporativismo com o campo da moralidade cristã, tida como civilizatória em nossa formação social. Nessa esfera de compreensão, os princípios de autoridade política, de harmonia de classes e mesmo de formação nacional encontravam na DSI o seu momento decisivo de justificação. Em que pese a dimensão compósita dessas dimensões, a "nova política social" - especialmente as leis trabalhistas seria justificada, no plano moral, pelos princípios doutrinários da Igreja, balizados pelos valores públicos correspondentes à alma nacional ${ }^{17}$. Dentre suas várias fontes e influências, é este momento das suas reflexões que nos interessa aprofundar nesta seção $0^{18}$.

Reportando-se às encíclicas Rerum novarum (1891) e Quadragésimo anno (1931), Vianna entendia que "É [...] absolutamente certo que o espírito que anima a nova política social se conforma plenamente com os princípios fundamentais desta grande doutrina" (1951, p. 30) ${ }^{19}$. Transcendendo a finalidade econômica e o "conforto material", a "redução das distâncias sociais" serviria a um valor humano maior: promover a elevação moral do trabalhador ${ }^{20}$. Traduzindo a "índole da nossa gente", o registro doutrinário cristão confrontaria, por meio das instituições corporativas, tanto o pragmatismo individualista liberal quanto o caráter classista e sedicioso que organizava o cânone marxista.

\footnotetext{
17 Além de Vieira (1976), a presença da DSI no interior da formulação intelectual de Vianna foi registrada por Gomes (2010; 1979) e Carvalho (1993). Aqui, enfatizamos apenas a maneira como a concepção católica de direitos pertence a uma ordem específica de justificação pública do pretendido rearranjo de interesses públicos e privados junto ao Estado.

18 A historiografia informa que a força e a penetração da intelectualidade e da militância católica na vida política e social brasileira das décadas de 1920 e de 1930 estruturou-se em torno da proposta de "recristianizar a sociedade brasileira". Difundindo esse projeto por meio de instrumentos como os periódicos A Ordem (1921) e Centro Dom Vital (1922) ou a Liga Eleitoral Católica e a Ação Católica Brasileira, o pensamento católico foi capaz de pautar a formação dos direitos sociais no país e marcar presença em agremiações laborais (Moura, 2012). No caso da revista A Ordem, o grupo mantenedor empenhou-se diretamente na criação dos "círculos operários", cujo "objetivo seria difundir os valores do catolicismo no seio da classe operária" (Arduini, 2012, p. 46).

19 Apesar de sua viva proximidade política e intelectual com a alta representação da Igreja, Vianna chegou a estabelecer polêmicas declaradas com esse campo. Em Problemas de direito sindical (Vianna, 1943), contrapõe-se à Ação Católica Brasileira ao recusar enfaticamente a formação de sindicatos confessionais e as pressões da cúria católica em favor do pluralismo sindical. Uma análise do "uso fragmentado" de suas fontes e influências pode ser encontrada em Vieira (1976) e em Campante (2001).

20 Nesse aspecto é possível identificar mais uma tensão analítica em Oliveira Vianna. Por vezes, o princípio corporativo católico comparece tanto como expressão da "cultura política nacional" quanto como elemento pedagógico e promotor de um civismo a ser alcançado.
} 
Segundo o autor, ao fundarem-se no conflito e não na harmonia social, tais concepções de mundo guardariam viva contradição com o "complexo cultural" do povo e da elite brasileira ${ }^{21}$.

Compreendemos que a influência católica sobre sua leitura do corporativismo não se colocava em conflito com os intensos diálogos promovidos pelo autor com a Escola Jurídica Americana ou com o campo da "Doutrina Europeia". Isso seria parte do seu "entrosamento de ideias", como destaca Vieira (1976). Entende-se, portanto, que uma coisa são suas influências quanto ao "funcionamento técnico jurisdicional" do corporativismo moderno, guiado, quase sempre, por Manoilescu, Perroux, Brandeis, Cardozo e Holmes (1938; 1943). Coisa bem distinta é a presença normativa da tradição católica, que, pontuada como uma "questão de princípio", pertence a problemas de outra natureza epistemológica. $\mathrm{Na}$ tradição católica, as instituições do trabalho seriam recepcionadas como lócus de formação cívica, cujo acesso a direitos sociais apenas traduziria o momento político necessário à alta formação ética da cidadania.

Todavia, mesmo enfatizando as responsabilidades do trabalhismo para com o bem comum, não se pode afirmar que exista em tal formulação uma cultura plenamente pública de direitos. Entende-se que no contexto em questão essa linguagem ainda não encontrava amplo desenvolvimento teórico e tinha dificuldades de se reafirmar no centro das preocupações políticas. A passagem citada a seguir, publicada em 1951, elucida a orientação normativa de Oliveira Vianna, esclarecendo como o "espírito público" comparecia no arranjo pretendido:

Realmente, êsses benefícios, que hoje garantem o trabalhador contra os riscos do trabalho, da moléstia ou da vida, não mais os recebe êle da piedade ou compaixão de um outro homem, rico e generoso, em esmolas humilhantes, nem dos estabelecimentos assistenciais custeados pelo Estado, nos quais ingresse degradado à condição de "indigente". Recebe-os, hoje, da sua instituição de previdência: da sua classe e para a qual concorre com a sua contribuição de associado. Não é mais recolhido aos hospitais do Estado - como um vencido; nem é forçado a comer a côdea de pão levada à sua trapeira pela caridade do patrão (Vianna, 1951, p. 123).

${ }^{21}$ É no interior dessa proposta de "harmonia social" que Oliveira Vianna justificaria sua forte preocupação em despolitizar as instituições sindicais. Uma análise dos muitos mecanismos legais criados para limitar a participação sindical no jogo político pode ser localizada em Werneck Vianna (1999). 
Nota-se que a "nova política social", além de objetivar a autonomia das camadas trabalhistas diante dos desmandos patronais, também demarcava os termos da dignidade pública, categoricamente distante de uma oferta simétrica e universal de direitos. Entende-se que a bifurcação referida pelo autor conforma, em larga medida, as distâncias teóricas e políticas entre a construção securitária na qual se deu a "saúde do trabalhador" e a formação da saúde pública no Brasil ${ }^{22}$.

Como se quer evidenciar, a estratificação do acesso aos direitos sociais no Brasil propunha-se, decisivamente, à construção e ao aperfeiçoamento de uma ética social, radicada em um ideal comunitário cristão. Por tais vias, se por um lado o programa político corporativo objetivava materializarse, inicialmente, no campo institucional-legal, por outro, era orientado para converter-se em procedimentos rotinizados, atingindo a condição de práxis política efetiva do trabalhismo. Nessa condição, impulsionando e moldando a "moralidade profissional", o programa se conformaria ao domínio público dos valores.

Esse olhar em relação à proximidade de Vianna com a DSI, dialogando com a fortuna crítica criada em torno de sua obra, nos permite confrontar a tese que o compreende como um "autoritário instrumental". Originariamente gestada por Santos na década de 1970, essa análise ganhou centralidade nos anos seguintes, comparecendo nos trabalhos de destacados interpretes do pensamento político brasileiro (Carvalho, 1993; Lamounier, 1977; Santos, 1994). O argumento básico desse campo consiste em perceber o arranjo de poder em Vianna como um momento de passagem à reafirmação de uma sociedade plenamente liberal no Brasil. Nesse caso, o autoritarismo seria um "instrumento transitório a que cumpre recorrer a fim de instituir no país uma sociedade diferenciada, capaz de dar suporte a instituições liberais autênticas" (Paim, 1987, p. 176).

Entende-se que essa interpretação só se sustenta ao preço de reduzirmos toda a tradição social católica à condição de aparelho "instrumental" do liberalismo. Condição essa que sufocaria o esforço de crítica ao pragmatismo

\footnotetext{
22 É interessante destacar que diversos historiadores do serviço social também apontam a existência de vínculos estreitos entre a origem desse campo de estudos e a presença dos fundamentos doutrinários católicos na formação da assistência à saúde (Aguiar, 1995; lamamoto e Carvalho, 2007; Yazbek, 2009). Todavia, como se quer documentar, a tradição social católica também se faz presente na organização do campo formal de direitos. Assim, conforme interpretação de Clark (2009, p. 63) sobre a Rerum novarum, essa distinção seria subsidiada pelos princípios de social justice e social charity.
} 
e ao individualismo liberal denunciados nas encíclicas católicas. No entanto, o corporativismo cristão, do qual se vale Vianna, funda-se na harmonia e na cooperação, submetendo o campo da produção a um ideal comunitário não conflitivo. Claramente, essa perspectiva societária não condiz com o ideal de liberdade que subsidia as linhagens do liberalismo contemporâneo (Vita, 2000).

A importância de demarcar a presença católica em Vianna como um campo teórico próprio incide, ainda, sobre dois planos: o primeiro refuta, no caso brasileiro, a ideia de que o regime celetista obedeça a uma inspiração obtusa da influência fascista; o segundo plano, mais amplo, abre o debate para se compreender a construção moderna de direitos para além da obra exclusiva de um liberalismo social ou de um socialismo reformista ${ }^{23}$. Por todos esses motivos, não nos parece adequado tomar esse suposto "legado ibérico" como um momento de passagem à sociedade liberal. Em outras palavras, seria possível complexar a modernidade e explicá-la para além das linguagens que se encontram mais consagradas na atualidade.

\section{Conclusão}

Esta análise demarca mais uma matriz que informa a origem polissêmica na qual se enraíza o pragmatismo corporativo na atualidade. Percorrendo a conjuntura dos anos 1920 aos de 1940, este artigo busca contribuir para a apreensão dos argumentos que demarcaram a legitimidade da luta segmentada por direitos. Caminho esse que acabou por envolver os rumos da atenção à saúde aos desígnios do mundo do trabalho.

Como expusemos, o pensamento e a práxis de Oliveira Vianna estiveram no centro das questões mais candentes que à época caracterizavam a vida política brasileira. Grosso modo, nossa pretensão foi a de acompanhar o processo que teria conduzido os argumentos desse autor ao centro de debates que disputavam a razão teórica e prática da política, antes de se alicerçarem no domínio da alta cultura. Percurso

\footnotetext{
${ }^{23}$ Transpondo o plano nacional, sabe-se que a tradição social cristã manteve influência na formação da própria Organização Internacional do Trabalho (OIT) (Gaze, Leão e Vasconcellos, 2011). O vulto de suas proposições também é identificado por Briggs (2000 [1961]) ao relatar a presença de partidos cristãos na formação de Estado de bem-estar. Como conclui Korpi (2008, p. 13):"Na Europa, instituições estatais corporativistas de seguridade social foram instaladas apenas em países com forte presença do catolicismo". Sobre esse assunto, ver também Kersbergen (1995) e Stephens (2001).
} 
esse que se revelou tortuoso e instável, uma vez que a chave corporativa não possuía aceitação majoritária quanto à resolução dos conflitos constitutivos daquele contexto.

Para além de atacar as assimetrias sociais, a "nova política social" procurou refirmar o universo corporativo como a melhor tradução do interesse público. Seria, assim, pelo mundo do trabalho formal que o cidadão passaria a existir no Brasil, deixando de ser uma categoria metafísica e livresca. A ambiguidade é que, ao fixar a cidadania por esse enquadramento, restariam "os idosos, as mulheres, os jovens e as crianças", categorias claramente vilipendiadas no mundo do trabalho. Essa condição se expressaria nas distintas competências institucionais atribuídas ao MTIC e o Mesp. Como tentamos evidenciar, incontornavelmente a "cidadania corporativa" assumia pisos largamente progressistas se comparada à situação anterior a 1930, o que não deve invisibilizar o seu caráter restritivo e segmentado.

No campo da saúde, a formação de duas portas ministeriais representava a condição inconsistente de uma "cultura pública de direitos". Nesse sentido, ao se organizar a "questão social" por uma chave corporativa, nota-se que a saúde do trabalhador deixava de ser compreendida como um campo da saúde pública. Integração essa que ainda enfrenta dificuldades de se reafirmar na atualidade.

\section{Referências}

AGUIAR, Antonio Geraldo de (1995). Serviço social e filosofia: das origens a Araxá. 5 ed. São Paulo: Cortez; Piracicaba: Universidade Metodista de Piracicaba.

AMARAL, Azevedo (1941). "Realismo político e democracia”. Cultura Política, n. 1, p. 157-73.

ARDUINI, Guilherme Ramalho (2012). “O Centro Dom Vital: estudo de caso de um grupo de intelectuais católicos no Rio de Janeiro entre os anos 1920 e 1940", em RODRIGUES, Candido Moreira \& PAULA, Jalles de (orgs). Intelectuais e militância católica no Brasil. Cuibá: EdUFMT.

BASBAUM, Leôncio (1976). História sincera da república (1889-1830). 4. ed. São Paulo: Alfa-Omega.

BOSI, Alfredo (1995). Dialética da colonização. São Paulo: Companhia das Letras. 
BOTELHO, André (2010). "Passado e futuro das interpretações do país". Tempo Social. v. 22, n. 1, p. 47-66.

BRIGGS, Asa (2000 [1961]). "Welfare State in historical perspective", em PIERSON, C. \& CASTLES, F. (eds.). The welfare State reader. Cambridge: Polity Press.

CAMPOS, Francisco (1940). O Estado nacional: sua estrutura, seu conteúdo ideológico. Rio de Janeiro: José Olympio.

CARONE, Edgard (1979). Movimento operário no Brasil (1887-1944). São Paulo: Difel.

CARVALHO, José Murilo (1993). “A utopia de Oliveira Vianna”, em BASTOS, E. R. \& MORAES, J. Q. (orgs.). O pensamento de Oliveira Vianna. Campinas (SP): Editora da Unicamp.

DIAS, Everardo (1977). História das lutas sociais no Brasil. 2. ed. São Paulo: Alfa-Omega.

FAUSTO, Boris (1983). Trabalho urbano e conflito social (1890-1920). 3. ed. São Paulo: Difel.

FERREIRA, Jorge \& GOMES, Ângela Castro (2001). O populismo e sua história: debate e crítica. Rio de Janeiro: Civilização Brasileira.

FONSECA, Cristina (2007). Saúde no Governo Vargas (1930-1945): dualidade institucional de um bem público. Rio de Janeiro: Fiocruz.

GAZE, Rosangela; LEÃO, Luis H. Costa \& VASCONCELLOS, Luis C. Fadel (2011). "A Organização Internacional do Trabalho: a saúde fora do lugar", em VASCONCELLOS, L. C. F. \& OLIVEIRA, M. H. B (orgs.). Saúde trabalho e direito: uma trajetória crítica e a crítica de uma trajetória. Rio de Janeiro: Educam.

GOMES, Ângela Castro (1979). Burguesia e trabalho: política e legislação social no Brasil, 1917-1937. Rio de Janeiro: Campus.

(1988). A invenção do trabalhismo. Rio de Janeiro: Iuperj.

(1993). "A extinção do imposto sindical: demandas e contradições". Dados, v. 36, n. 2, p. 317-52.

(2010). "Oliveira Vianna: o Brasil do insolidarismo ao corporativismo”, em LIMONCIC, F. O. \& MARTINHO, F. C. P. (orgs.). Os intelectuais do antiliberalismo: projetos e políticas para outras modernidades. Rio de Janeiro: Civilização Brasileira.

HOLANDA. Sérgio Buarque de (1979). Tentativas de mitologia. São Paulo: Perspectiva. 
IAMAMOTO. Marilda Villela \& CARVALHO, Raul de (2007). Relações sociais e serviço social no Brasil: esboços de uma interpretação histórico-metodológica. 21. ed. São Paulo: Cortez; Lima: Celats.

KORPI, Walter (2008). Origins of welfare States: changing class structures, social democracy, and christian democracy. Stockholm: Swedish Institute for Social Research, Stockholm University.

LAMOUNIER, Bolívar (1977). "Formação de um pensamento político autoritário na Primeira República: uma interpretação", em FAUSTO, Boris (org.). História geral da civilização brasileira, tomo. III: O Brasil republicano, v. 2: Sociedade e instituições (1889-1930). Rio de Janeiro: Difel. LOWY, Michael (1980). "Do movimento operário independente ao sindicalismo de Estado (1930-1945)", em SADER, Eder et al. Movimento operário brasileiro: 1900/1979. Belo Horizonte: Vega.

MALLOY, James M. (1976). "Previdência social e classe operária no Brasil”. Estudos Cebrap, n. 15, jan.-mar., p. 118.

MOURA, Carlos André Silva (2012). "Restaurar todas as coisas em Cristo': Dom Sebastião Leme e os diálogos com os intelectuais durante o movimento de recatolização no Brasil (1916-1942)", em RODRIGUES, Candido Moreira \& PAULA, Jalles de (orgs). Intelectuais e militância católica no Brasil. Cuibá: EdUFMT.

OLIVEIRA, Lucia Lippi (1993). "Uma leitura das leituras de Oliveira Vianna”, em BASTOS, E. R. \& MORAES, J. Q. (orgs.). O pensamento de Oliveira Vianna. Campinas (SP): Editora da Unicamp.

PAIM, Antônio (1987). "Oliveira Vianna e o pensamento autoritário no Brasil”, em VIANNA, Oliveira. Instituições políticas brasileiras. v. 2. 4. ed. Belo Horizonte: Itatiaia.

REIS, Fabio Wanderley (1989). "Estado, política social e corporativismo". Revista Fundação João Pinheiro, v. 4, n. 1, p. 87-94. (2000). Mercado e utopia. São Paulo: Edusp.

RIQUELME, Sérgio Fernández (2009). "La era del corporativismo: la representación jurídico-política del trabajo en la Europa del siglo XX”. Revista de Estudios Histórico-Jurídicos, n. 31, p. 399-425.

RODRIGUES, Leôncio Martins (1969). Socialismo e sindicalismo no Brasil. Rio de Janeiro: Laemmert.

RODRIGUEZ, Ricardo Velez (1997). Oliveira Vianna e o papel modernizador do Estado brasileiro. Londrina (PR): Eduel. 
SANTOS, Wanderley Guilherme dos (1994). Cidadania e justiça: a política social na ordem brasileira. 3. ed. Rio de Janeiro: Campus.

SCHWARTZMAN, Simon (1982). Bases do autoritarismo brasileiro. Rio de Janeiro: Campus (Contribuições em Ciências Sociais, n. 10).

SEGATTO, José Antônio (1989). Breve historia do PCB. 2. ed. Belo Horizonte: Oficina de Livros.

SOUZA, Ricardo Luiz de (2005). "Nacionalismo e autoritarismo em Alberto Torres". Sociologias, v. 7, n. 13, p. 302-23.

STEPHENS, John D. \& HUBER, Evelyne (2001). Development and crisis of the welfare State: parties and policies in global. Chicago: University Chicago. VIANNA, Luis Werneck (1999). Liberalismo e sindicato no Brasil. 4. ed. Belo Horizonte: Editora UFMG.

VIANNA, Oliveira (1930). Problemas de política objetiva. São Paulo: Companhia Editora Nacional.

(1938). Problemas de direito corporativo. Rio de Janeiro: José Olympio. (1943). Problemas de direito sindical. Rio de Janeiro: Max Limonad. (1949a). Instituições políticas brasileiras, v. 1: Fundamentos sociais do Estado. Rio de Janeiro: José Olympio.

(1949b). Instituições políticas brasileiras, v. 2: Metodologia do direito público. São Paulo: José Olympio.

(1951). Direito do trabalho e democracia social: o problema da incorporação do trabalhador no Estado. Rio de Janeiro: José Olympio.

(1991). Ensaios inéditos/Oliveira Vianna. Campinas (SP): Editora da Unicamp.

VIEIRA, Evaldo Amaro (1976). Oliveira Vianna e o Estado corporativo: um estudo sobre corporativismo e autoritarismo. São Paulo: Grijalbo.

VITA, Álvaro (2000). A justiça igualitária e seus críticos. São Paulo: Editora Unesp.

YAZBEK, Maria Carmelita (2009). "Fundamentos históricos e teórico-metodológicos do Serviço Social”, em CFESS \& Abepss (orgs.). Serviço social: direitos e competências profissionais. Brasília: CFESS, Abepss.

WEIR, Margareth (1992). "Ideas and the politics of bounded innovation", em Steinmo, SVEN; THELEN, Kathleen \& LONGSTRETH, Frank (eds.). Structuring politics: historical institucionalism in comparative analysis. New York: Cambridge University Press. 


\section{Resumo}

Esse artigo se ocupa do processo de inscrição da linguagem corporativa no trabalhismo brasileiro. Para tanto, problematiza o seu desenvolvimento no campo dos valores públicos e das instituições, atribuindo relevo à relação entre a saúde do trabalhador e a política de saúde pública. A partir da historicização desse fenômeno político, recupera-se o dissenso intelectual dos anos 1930, localizando na proximidade de Oliveira Vianna com paradigma social católico um momento privilegiado para sua legitimação pública. Com esse enquadramento histórico-analítico a contribuição do artigo consiste em apresentar argumentos que desestabilizam as interpretações que assumem o pragmatismo corporativo como condição inexorável do trabalhismo moderno.

Palavras-chave: corporativismo; interesse público; política de saúde; trabalhismo.

\section{Abstract}

This article is concerned with the process of inscription of corporate language in Brazilian Labor movement. For that, it discusses its development in the field of public values and institutions, stressing the relationship between workers' health and public health policy. By historicizing such political phenomenon, the paper recovers the intellectual dissent of the 1930s, pointing out Oliveira Vianna's proximity to the social catholic paradigm as a privileged moment for its public legitimation. With this historical-analytical framework, the article's contribution consists in presenting arguments that destabilize interpretations that assume corporate pragmatism as an inexorable condition of modern labor movement. Keywords: corporatism; public interest; health policy; labor movement.

Recebido em 31 de dezembro de 2013.

Aprovado em 27 de abril de 2015. 